\title{
Factors influencing minority student decisions to consider a career in evolutionary biology
}

\author{
Louise S Mead $^{1 *}$, Judi Brown Clarke ${ }^{1}$, Frank Forcino ${ }^{2}$ and Joseph L Graves Jr ${ }^{3}$
}

\begin{abstract}
Background: Without an understanding of evolution, members of the public are unlikely to fully grasp many important issues necessary for the understanding science. In addition, evolutionary science plays an important role in advancing many other STEM disciplines. In stark contrast to the importance of the evolutionary sciences, is its enigmatic acceptance by the general American public. This acceptance is also not uniform within African American, Hispanic, and American Indian populations, who show higher rates of rejection of evolutionary reasoning. In an effort to advance our scientific community, it is imperative that we recruit highly quality students from an ever-increasing diverse population. Thus, the field is failing to attract and maintain the diversity desired in America's scientific workforce with the above-mentioned minority groups, which are even further underrepresented in evolutionary science.
\end{abstract}

Methods: To examine why underrepresented minorities may not choose careers in evolutionary sciences, we surveyed 184 people who have chosen to pursue a career in science. The two questions we examined were: (1) what factors influence the career choices of underrepresented minorities (URMs) interested in science? and (2) what factors influence these URM students to choose careers in other sub-disciplines in biology rather than careers in evolutionary science? A survey was created from previously published research, and our analysis examined statistical differences between different racial/ethnic groups.

Results: Our data suggest there are significant differences among racial/ethnic groups in factors that appear to influence their career paths, specifically African Americans and non-Puerto Rican Hispanic/Latino(a)s place greater emphasis on the presence of people of similar racial/ethnic background. Additionally we found differences between the URM groups in terms of their interest in, and understanding of, evolutionary biology; which appears to result in less likelihood of choosing careers in evolutionary science. And for some African Americans, reluctance to pursue evolutionary biology may be tied to holding misconceptions about evolution and higher levels of religiosity.

Conclusions: Our current work is preliminary, but once there is a better understanding of why URMs do not pursue evolutionary science, strategic steps can be taken to overcome these barriers. When an inclusive culture is at work, a diverse scientific team becomes capable of producing a broad range of original and engaging ideas not possible among homogenous groups. Educators, researchers, and equality advocates will be able to target the specific causes of underrepresentation in the evolutionary sciences and improve representation of racial and ethnic minorities in evolutionary science, to the ultimate benefit of the greater scientific community and the world at large.

Keywords: Diversity; Underrepresentation

\footnotetext{
* Correspondence: Ismead@msu.edu

${ }^{1}$ BEACON Center for the Study of Evolution in Action, Michigan State

University, 567 Wilson Ave BPS 1441, East Lansing, MI, 49925, USA

Full list of author information is available at the end of the article
} 


\section{Background}

Despite the vast and ever-increasing evidence for the theory and fact of evolution (Gregory 2008), and overwhelming acceptance among scientists, many factions of American society continue to show low rates of acceptance of evolution (Table 1) (Pew Research 2009; Pew Research 2013; Gallop News 2014), and rates in the U.S. are among the lowest of many industrial countries (Miller et al. 2006). These data are not new to any of us working in the field of evolution education. Polls (Pew Research 2013) and studies (Fuerst 1984; Ingram and Nelson 2006; Paz-y-Minos and Espinosa 2009b; Rice et al. 2011) suggest understanding of evolution increases

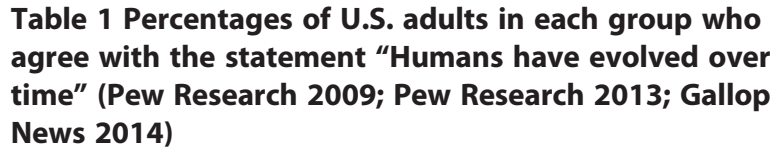

College grad

Religious Affiliation:

White evangelical Protestants 27-29

Black Protestants 44-46

Hispanic Catholic 48-53

White Catholic 66-68

White mainline Protestants 63-78

Unaffiliated $\quad$ 75-76

Political affiliation:

Republicans $\quad 43-49$

Democrats $\quad$ 58-67

Independents 65-67

Religious attendance:

Weekly or more 25-35

Monthly/yearly $\quad$ 48-60

Seldom/never 66-70

Ranges reflect variation in polls and populations sampled. with years of education, therefore one might expect levels of evolution acceptance to be high among college students, particularly those interested in the STEM (science, technology, engineering, and mathematics) disciplines. However, a review of studies investigating evolution acceptance among undergraduate students (see Additional file 1: Table S1) suggests low rates of acceptance of evolution, even among the STEM student population (Blackwell et al. 2003; Rutledge and Sadler 2007). These studies also suggest a positive relationship between understanding science and acceptance of evolution (Fuerst 1984; Lombrozo et al. 2008), and a negative relationship between religiosity and acceptance of evolution (Lombrozo et al. 2008; Bailey et al. 2011; Paz-y-Minos and Espinosa 2009a; Paz-y-Miño and Espinosa 2011; Rissler et al. 2014). A recent study suggests that religiosity is even more important factor than education (Rissler et al. 2014). Whereas many studies focus on religiosity as the main driver, others attempt to delineate additional factors influencing evolution acceptance (Brem et al. 2003; Sinatra et al. 2003; Hawley et al. 2011). We discovered that many studies sample populations that include racial/ethnic minority students, however few of them disaggregate evolution acceptance by race/ethnicity. In contrast, Bailey et al. (2011) did disaggregate minority student responses and found greater religiosity among African American students compared to non-African Americans, and this was negatively correlated with evolution acceptance. Surprisingly, however, Bailey et al. (2011) also found a negative correlation between knowledge of evolution and acceptance of evolution; the more students appeared to know about evolution, the less likely they were to accept evolution. These results suggest it may be important to evaluate racial/ethnic differences in evolution acceptance and understanding, particularly if recruitment and retention of underrepresented minority (URM) students in STEM disciplines that apply or require evolutionary reasoning is a priority.

Evolutionary science informs a wide range of science and technology facets within US society (Larder et al. 1989; Back 1996; Nesse and Williams 1996; Khachatourians 1998; Dufour 2006; Perron et al. 2006; Pike and Williams 2006; Coello et al. 2007; Graves 2011). In contrast to the importance of the evolutionary sciences, it is clearly not gaining acceptance among college-educated students; and equally disturbing, it is failing to attract and maintain the diversity desired in America's scientific workforce with African Americans, Hispanics, and American Indians, which are significantly underrepresented in evolutionary science compared with many other sciences. In 2011, within the broad field of biological sciences, the largest numbers of doctoral degrees were awarded in neuroscience, biochemistry, and molecular biology, with the distribution of European Americans, Hispanics, and African 
Americans receiving degrees in these fields as follows: neuroscience: $535,49,32$; biochemistry: $377,39,26$; and molecular biology: $365,35,23$. Across each of these fields the proportions are relatively consistent ( $86 \%$ of degrees were awarded to European Americans, $8 \%$ were awarded to Hispanics, and 5\% awarded to African Americans. In stark comparison, the numbers of individuals receiving doctoral degrees in evolutionary biology by ethnicity were 135, 8, and 0 (NSF/NIH/USED/USDA/NEH/NASA Survey of Earned Doctorates 2011). Overall, not only were there substantially fewer students receiving degrees in evolutionary biology, when compared to these three most popular disciplines only $9 \%$ of all degrees were awarded in evolutionary biology, the distribution of degrees within racial/ethnic groups was also quite different. The ratio of European Americans, Hispanics, and African Americans receiving doctoral degrees in evolutionary biology as compared to the other disciplines was $0.11,0.06$, and 0.00 , respectively. European Americans were twice as likely to pursue a degree in evolutionary biology as compared to Hispanics, and no African Americans received a degree in this field in 2011. We recognize this is just a snapshot and that governmental agencies have just begun to record Ph.D. attainment by race/ethnicity, however the small numbers of African Americans and Hispanics in professional evolutionary science careers strongly suggests this situation is not new. We also have personal observations of the field from the last quarter century indicating that the snap shots are an accurate reflection of its demography (Graves 2012).

A number of studies have identified factors influencing career choices and the success of URM students in the STEM disciplines (Chemers et al. 2011; Eccles 2011; Jaeger et al. 2013; MacPhee et al. 2013; Merolla and Serpe 2013; Thoman et al. 2014), but little is known about the attitudes of URM students toward evolutionary biology, and how these views might influence their decisions to pursue STEM disciplines that require a working understanding of this fundamental concept. We therefore sought to generate information about evolution acceptance and knowledge as potential variables impacting the career choices of undergraduate students who already show an interest in pursuing a career path in science. To study the reasons for science career choice, we created a survey to examine the factors that (1) influence the career choices of underrepresented minorities (URMs) interested in science, and (2) may influence these URM students to choose careers in other sub-disciplines in biology rather than careers in evolutionary science.

\section{Methods}

\section{Sample population}

Surveys were administered to participants at two scientific conferences, the Annual Biomedical Research Conference for Minority Students (ABRCMS) in November 2013 and the National Conference of the Society for the Advancement of Chicanos and Native Americans in Science (SACNAS) in October 2103. These two conferences differ considerably with regard to the demography of student attendees. Students attending ABRCMS are primarily African Americans, whereas SACNAS participants are primarily Latinos (Mexican American, Puerto Rican, etc.) and American Indians. We chose to focus on these student populations because most are already engaged in scientific research, and therefore represent an excellent source of URM students committed to STEM careers. We understood that these participants would not necessarily be representative of either the attitudes towards, or knowledge of, evolution we would expect to find in the general population of underrepresented minority (URM) students.

At both conferences, the survey was administered via a booth run by the BEACON Center for the Study of Evolution in Action. We asked all visitors to the booth to complete the survey. While we targeted undergraduates, our sample did include a few individuals with degrees, and a few faculty members as well. Everyone surveyed who met the criteria were included regardless of level of education (six participants had completed a $\mathrm{PhD}$ ). We collected all data following Michigan State University Institutional Review Board guidelines, IRB \#i040365.

\section{Survey instrument}

To assess career choice, religiosity, and evolution understanding, we created a 65 -item survey with items belonging to four general categories of social dynamic hypotheses: Religiosity (R); Educational Background (EB); Career Choice Factors (CCF); and Evolution Understanding (UE). In order to examine if our surveyed variables (individual variables and constructs) had any effect on choice of career, we used an open-ended question to identify a student's desired career discipline. These responses were then classified into five categories: evolutionary sciences, general biology, medicine, physical sciences (chemistry/physics), and other science (e.g., Earth sciences). Students choosing computer science and engineering were not included in this analysis.

Items assessing Religiosity were taken from the Evolution Attitudes and Literacy Survey (EALS; Hawley et al. 2011), and we maintained their scale of 1 to 7 for consistency and future comparison with previously collected EALS data. The remaining items were also Likert-type questions, scaled from 1 to 5 , and developed to address our preliminary questions. The second category inquired about the person's schooling, with specific reference to training in evolutionary biology. The third category examined possible reasons for career selection, information 
about the people or other sources of influence for career selection, and familiarity with other URMs in their chosen field. The final category assessed understanding of basic evolutionary processes. We developed statements based on preliminary surveys administered to undergraduates and experts. The complete 65-question survey is available in the Additional file 2: Table S2.

\section{Statistical analyses}

In order to determine which sets of questions were gathering similar information, factor analyses were conducted separately on the groups of items within each of the categories listed above. The goal of the factor analyses was to gauge the appropriateness of analyzing each group of items as one construct. The five constructs we were attempting to measure when the items were written were (1) influence from friends, family, and loved ones; (2) influence from teachers, mentors, and other educators; (3) influences from pop culture and media sources; (4) religiosity; and (5) evolution understanding. All factor analyses were run in R 3.0.2 (R Development Core Team 2013) with the factanal function using maximum likelihood and a varimax rotation.

The evolution understanding items have not been previously published or tested for validity and reliability. Thus, the factor analysis of the evolution understanding items will also serve as a test for validity and reliability among our population.

In addition to the five major constructs examined in the factor analyses, other single items from the survey were included in the statistical analyses to examine differences among racial/ethnic groups and career choice (e.g., evolution, biology, or medicine). In order to examine if there were any differences in response to surveyed variables by race/ethnicity, a series of ANOVAs were conducted using the self-identified race/ethnicity as selected from nine ("choose all that apply") choices by the participants. For the ANOVAs examining career choice, the open-ended stated area of study was categorized and used. For all ANOVAs that resulted in a significant difference at $\mathrm{p}<0.05$, Bonferroni-corrected pairwise $\mathrm{t}$-tests were conducted to test which specific groups were significantly different from one another.

\section{Results}

A total of 184 people attending either the ABRCMS in November 2013 or the Annual SACNAS Conference in October 2013 completed the survey. Our sample included 68 males, 115 females, and 1 other. The self-reported racial/ethnic background of people completing the surveys was 89 Hispanic/Latino(a) (48.4\%), 38 African American (20.7\%), 22 "other" (11.9\%), 19 European American (10.3\%), 11 American Indian (6.0\%), and 5 "no response" (2.7\%) (Table 2). Only a few participants self-reported as Asian/ Asian American or Middle Eastern/Middle Eastern American; we therefore categorized these as "other" because of the small sample size, and our specific interest in underrepresented minorities (URM) as defined by the National Science Foundation. Current level of education of survey participants included 2 high schoolers, 4 freshmen, 22 sophomores, 47 juniors, 75 seniors, and 5 in grad school for masters' degrees, 17 in graduate school for Ph.Ds. In addition, 6 had completed MS degrees and 6 had completed Ph.Ds.

Based on our categorization of self-identified career pursuit (Table 2), 117 indicated biology. This category did not include those indicating evolutionary biology $(n=9)$, nor did it include those planning to become medical doctors or veterinarians $(n=22)$. However, the biology category did include those pursing medical science research or medical academic careers (e.g., neuroscience research). The remaining respondents indicated interest in physics/chemistry $(\mathrm{n}=22)$, other science disciplines (e.g., Earth science, oceanography, environmental science, astronomy) $(\mathrm{n}=14)$.

\section{Factors influencing career choices}

Personal factors-Three different constructs of personal factors and influences were predicted based on various groups of survey items. These three constructs (i.e., (1) influence from friends, family, and loved ones; (2) influence from teachers, mentors, and other educators; and (3) influences from pop culture and media sources) were examined in separate factor analyses because we wanted to compare them, as separate constructs, to career choice and race/ethnicity. The items in each of these three constructs strongly factored together (Table 3 ) indicating that

Table 2 Total number of participants completing surveys according to racial/ethnic identity and career choice

\begin{tabular}{lccccccc}
\hline & Latino(a)/Hispanic & African Americans & Other & European American & American Indian & No answer & Total \\
\hline Biology & 57 & 23 & 13 & 12 & 7 & 3 & $117(63.6 \%)$ \\
Medicine & 7 & 8 & 4 & 1 & 2 & $22(11.9 \%)$ \\
Phys/Chem & 14 & 1 & 3 & 2 & 2 & 0 & $22(11.9 \%)$ \\
Other & 4 & 5 & 1 & 2 & 0 & 0 & $14(7.6 \%)$ \\
Evolution & 7 & 1 & $22(11.9 \%)$ & $19(10.3 \%)$ & $11(6.0 \%)$ & $5(2.7 \%)$ & $184(100 \%)$ \\
Total & $89(48.4 \%)$ & $38(20.6 \%)$ & & & & 2 & 0 \\
\hline
\end{tabular}


Table 3 Factor analysis for Friends and family; Teachers and mentors; Popular culture

\begin{tabular}{|c|c|c|c|}
\hline General construct & Item & Factor & Loadings \\
\hline \multirow[t]{18}{*}{ Friends and family } & \multirow{4}{*}{$\begin{array}{l}\text { Please rate the importance of each of the following } \\
\text { people or factors in informing you about career choices }\end{array}$} & Parent or guardian & 0.6 \\
\hline & & Other family member & 0.568 \\
\hline & & Community member & 0.456 \\
\hline & & Pop culture & 0.4 \\
\hline & \multirow{2}{*}{$\begin{array}{l}\text { Rate the influence of each of the following factors } \\
\text { on your choice of career path. }\end{array}$} & Support or influence of a family member & 0.597 \\
\hline & & Forced into by family or loved one & 0.447 \\
\hline & \multirow{6}{*}{$\begin{array}{l}\text { How would you rate the support for your current } \\
\text { work in your scientific discipline? }\end{array}$} & From your parent(s) or guardian(s) & 0.46 \\
\hline & & From your sibling(s) & 0.459 \\
\hline & & From other family member(s) & 0.408 \\
\hline & & From your peer(s) & 0.384 \\
\hline & & From coworker(s) & 0.349 \\
\hline & & From other community members & 0.419 \\
\hline & \multirow{6}{*}{$\begin{array}{l}\text { How would you rate the disapproval to your current } \\
\text { work in your scientific discipline? }\end{array}$} & From your parent(s) or guardian(s) & 0.788 \\
\hline & & From your sibling(s) & 0.767 \\
\hline & & From other family member(s) & 0.81 \\
\hline & & From your peer(s) & 0.715 \\
\hline & & From coworker(s) & 0.661 \\
\hline & & From other community members & 0.657 \\
\hline \multirow[t]{11}{*}{ Teachers and mentors } & \multirow{4}{*}{$\begin{array}{l}\text { Please rate the importance of each of the following } \\
\text { people or factors in informing you about career choices }\end{array}$} & High school teacher or instructor & 0.568 \\
\hline & & High school advisor & 0.444 \\
\hline & & Undergraduate instructor & 0.53 \\
\hline & & Undergraduate advisor & 0.557 \\
\hline & $\begin{array}{l}\text { Rate the influence of each of the following factors on } \\
\text { your choice of career path. }\end{array}$ & Support or influence of a non-related mentor & 0.509 \\
\hline & \multirow{3}{*}{$\begin{array}{l}\text { How would you rate the support for your current } \\
\text { work in your scientific discipline? }\end{array}$} & From your teacher(s) & 0.601 \\
\hline & & From your mentor(s) & 0.603 \\
\hline & & From your role model(s) & 0.585 \\
\hline & \multirow{3}{*}{$\begin{array}{l}\text { How would you rate the disapproval to your current } \\
\text { work in your scientific discipline? }\end{array}$} & From your teacher(s) & 0.69 \\
\hline & & From your mentor(s) & 0.749 \\
\hline & & From your role model(s) & 0.706 \\
\hline \multirow[t]{4}{*}{ Popular culture } & \multirow{2}{*}{$\begin{array}{l}\text { Please rate the importance of each of the following } \\
\text { people or factors in informing you about career choices }\end{array}$} & Popular culture (e.g. TV, movies) & 0.713 \\
\hline & & News & 0.701 \\
\hline & \multirow[t]{2}{*}{$\begin{array}{l}\text { Rate the influence of each of the following factors } \\
\text { on your choice of career path }\end{array}$} & $\begin{array}{l}\text { Visits to science museums, aquaria, planetariums, } \\
\text { nature preserves }\end{array}$ & 0.384 \\
\hline & & $\begin{array}{l}\text { Popular media or personalities (e.g. NOVA, Neil } \\
\text { deGrasse Tyson, Bill Nye) }\end{array}$ & 0.544 \\
\hline
\end{tabular}

each group of items can be used to compare with career choice and racial/ethnic identity.

For the family and friends construct, all factor loadings were above the common threshold of 0.32 (Table 3). One factor was satisfactory for examining this construct because there was a steep drop-off illustrated in the scree plot from the first eigenvalue factor to the second. The first factor explained $37 \%$ of the variance. The KaiserMeyer-Olkin measure of sampling adequacy was 0.84 , and Bartlett's test of sphericity was significant $\left(X^{2}(153)=\right.$
2033.415, $\mathrm{p}<0.001)$. In addition, the Cronbach's Alpha was 0.90 .

For the teachers and mentors construct, all factor loadings were above the common threshold of 0.32 (Table 3). One factor was satisfactory for examining this construct because there was a steep drop off illustrated in the scree plot from the first eigenvalue factor to the second. The first factor explained $36 \%$ of the variance. The Kaiser-Meyer-Olkin measure of sampling adequacy was 0.77, and Bartlett's test of sphericity was significant 
$\left(X^{2}(55)=1093.187, \mathrm{p}<0.001\right)$. The Cronbach's Alpha was 0.86 .

For the popular culture construct, all factor loadings were above the common threshold of 0.32 (Table 3). One factor was satisfactory for examining this construct, again, there was a steep drop off illustrated in the scree plot from the first eigenvalue factor to the second. The first factor explained $44 \%$ of the variance. The KaiserMeyer-Olkin measure of sampling adequacy was 0.71 , and Bartlett's test of sphericity was significant $\left(\mathrm{X}^{2}(10)=\right.$ 323.948, $\mathrm{p}<0.001)$. The Cronbach's Alpha was 0.79 .

Religiosity-The religiosity items taken from the Evolution Attitudes and Literacy Survey (EALS; Hawley et al. 2011) factored together (Table 4). One factor was satisfactory for examining this construct because there was only one eigenvalue greater than one and there was a steep drop off illustrated in the scree plot from the first eigenvalue factor to the second. The first factor explained $74 \%$ of the variance. The Kaiser-Meyer-Olkin measure of sampling adequacy was 0.87 , and Bartlett's test of sphericity was significant $\left(\mathrm{X}^{2}(10)=852.189, \mathrm{p}<0.001\right)$. The Cronbach's Alpha was 0.93 .

\section{Evolution understanding}

The 12 evolution content items that were used to assess evolution understanding have not been published previously. Each of the 12 Likert-type items was examined in a factor analysis resulting in two different factors (Table 4). The eigenvalues for the two factors were both above one. The first factor explained $23 \%$ of the variance, and the second factor explained an additional $16 \%$. The Kaiser-Meyer-Olkin measure of sampling adequacy was 0.81 , and Bartlett's test of sphericity was significant $\left(\mathrm{X}^{2}(66)=705.146, \mathrm{p}<0.001\right)$. In addition, the Cronbach's Alpha was 0.80 . These two factors broadly correspond to misconceptions (Factor 1) and basic evolutionary processes (Factor 2). Answering in agreement with items in Factor 1 would indicate an individual holds common misconceptions about evolution in general. Answering in agreement to items in Factor 2 would suggest a good understanding of the basic processes required for evolution.

\section{Comparisons among groups}

Racial/ethnic group comparisons-When choosing a science discipline within which to pursue as a career, our data suggest African Americans and non-Puerto Rican Latino(a)s are more strongly influenced by the presence of people in that chosen discipline that identify as being part of the same racial/ethnic group (African Americans: $\mathrm{p}=0.02$; non-Puerto Rican Latino(a)s: $\mathrm{p}=0.01$ ) as compared with European Americans (Table 5). European

Table 4 Factor analysis for Religiosity and Evolution Understanding

\begin{tabular}{|c|c|c|c|}
\hline General construct & Item & & Loadings \\
\hline \multirow[t]{7}{*}{ Religiosity } & To what degree & & \\
\hline & ..are you religious & & 0.971 \\
\hline & ...does your religion influence your decisions? & & 0.864 \\
\hline & ...do you participate in religious activities? & & 0.921 \\
\hline & ... is the following statement true? I believe in god(s) & & 0.694 \\
\hline & $\begin{array}{l}\text { Religion is especially important to me because it answers many of my questions about } \\
\text { the meaning of life. }\end{array}$ & & 0.839 \\
\hline & Item & $\begin{array}{l}\text { Factor } 1 \\
\text { Loadings }\end{array}$ & $\begin{array}{l}\text { Factor } 2 \\
\text { Loadings }\end{array}$ \\
\hline \multirow[t]{12}{*}{ Evolution Understanding } & The genetics of a population of organisms remains the same over time & 0.545 & 0.17 \\
\hline & Evolution cannot ever be observed because it happens over very long periods of time. & 0.778 & 0.184 \\
\hline & Evolution is generally only observable in organisms that take less than a day to reproduce. & 0.673 & 0.187 \\
\hline & Evolutionary biology does not investigate testable ideas about the natural world & 0.807 & 0.258 \\
\hline & Evolution means progression towards perfection & 0.391 & \\
\hline & $\begin{array}{l}\text { Characteristics acquired during the lifetime of an organism are passed down to an } \\
\text { individual's offspring }\end{array}$ & 0.358 & \\
\hline & Evolution is a linear progression from primitive to advanced species. & 0.541 & \\
\hline & In most populations, more offspring are born than can survive. & & 0.424 \\
\hline & Mutations can be passed down to the next generation. & 0.218 & 0.568 \\
\hline & Increased genetic variability makes a population more resistant to extinction. & 0.114 & 0.713 \\
\hline & The more recently species share a common ancestor the more closely related they are. & 0.207 & 0.705 \\
\hline & Mutations occur all the time. & 0.163 & 0.543 \\
\hline
\end{tabular}


Table 5 ANOVA and Bonferroni corrected t-tests for racial/ethnic comparisons

\begin{tabular}{|c|c|c|c|c|c|c|c|c|c|}
\hline & \multicolumn{3}{|c|}{ ANOVA } & \multicolumn{6}{|c|}{ Bonferroni corrected t-tests } \\
\hline & F-stat & df & $\mathbf{p}$ & & & & & & \\
\hline \multirow{3}{*}{$\begin{array}{l}\text { Career path influenced by presence of people of similar socio/ } \\
\text { economic or racial/ethnic background }\end{array}$} & 2.519 & 175 & 0.03 & & AA & Lat/His & NA & PR & Other \\
\hline & & & & $\mathrm{EA}$ & 0.03 & 0.01 & 1.00 & 1.00 & 1.00 \\
\hline & & & & $P R$ & 0.36 & 0.22 & 1.00 & -- & 1.00 \\
\hline \multirow[t]{2}{*}{ When were you first exposed to evolutionary sciences? } & 2.344 & 176 & 0.04 & & AA & Lat/His & NA & PR & Other \\
\hline & & & & EA & 0.477 & 0.335 & NS & 0.02 & 0.355 \\
\hline \multirow{2}{*}{$\begin{array}{l}\text { Why/how did you first become interested in sciences? From } \\
\text { your parents/guardians }\end{array}$} & 3.233 & 177 & 0.008 & & $A A$ & Lat/His & NA & & \\
\hline & & & & EA & 0.09 & 0.05 & 0.01 & $\mathrm{~N} / \mathrm{a}$ & \\
\hline \multirow{3}{*}{$\begin{array}{l}\text { Please rate your agreement with the following statement: } \\
\text { Evolutionary science is a valid academic discipline. }\end{array}$} & 3.222 & 178 & 0.008 & & $\mathrm{AA}$ & Lat/His & NA & & Other \\
\hline & & & & EA & 0.20 & 0.60 & 1.00 & N/a & 0.005 \\
\hline & & & & Lat/His & 1.00 & -- & 1.00 & $\mathrm{~N} / \mathrm{a}$ & 0.16 \\
\hline \multirow[t]{4}{*}{ Religiosity } & 7.122 & 171 & $<0.001$ & & AA & Lat/His & NA & & Other \\
\hline & & & & EA & $<0.001$ & 1.00 & 1.00 & $\mathrm{~N} / \mathrm{a}$ & 1.00 \\
\hline & & & & Lat/His & 1.00 & -- & 1.00 & $\mathrm{~N} / \mathrm{a}$ & 1.00 \\
\hline & & & & AA & -- & $<0.001$ & 0.09 & $\mathrm{~N} / \mathrm{a}$ & 0.04 \\
\hline \multirow[t]{3}{*}{ Understanding (Factor 1) } & 2.322 & 175 & 0.05 & & AA & Lat/His & NA & & Other \\
\hline & & & & EA & 0.05 & 0.29 & 1.00 & $\mathrm{~N} / \mathrm{a}$ & 1.00 \\
\hline & & & & AA & -- & 1.00 & 0.39 & N/a & 1.00 \\
\hline
\end{tabular}

${ }^{*} \mathrm{AA}=$ African Americans, Lat/His = Latino(a)/Hispanic, NA = Native American, EA = European American, PR = Puerto Rican.

Americans were significantly more likely to gain interest in science from their parent or guardian compared with Native Americans $(p=0.01)$ and Latino(a)s/Hispanics $(\mathrm{p}=0.05)$. In addition, European Americans were exposed to evolutionary sciences earlier, in middle school, with a significant difference found for the comparison with Puerto Ricans, who report first being exposed to evolutionary science in late high school $(p=0.02)$. We also found a significant difference in agreement with the idea that evolutionary science is a valid academic discipline, European Americans showed a significant difference from those classified as "other" in our study.

African Americans exhibit higher rates of religiosity than all other racial/ethnic groups (Table 5) and there was a significant difference between African Americans and both European Americans $(\mathrm{p}<0.001)$ and Latino(a)s/ Hispanics $(\mathrm{p}<0.001)$. With respect to understanding evolution, African Americans exhibited a significantly lower understanding of evolution (Table 6) than European Americans $(\mathrm{p}=0.05)$.

\section{Career choice comparisons}

We found a significant difference between students pursing a career in medicine as compared to evolutionary biology, in their perception of the importance of evolutionary science to our global society (Table 6). Not surprisingly, we also found differences among groups in their current level of interest in evolutionary science, those students pursing evolutionary biology were more interested in the discipline compared to students pursing general biology, medicine, or a physical science.

Students in evolutionary biology were also significantly less religious than those in biology $(\mathrm{p}=0.03)$ or medicine $(\mathrm{p}<0.001)$. Students interested in medicine indicated higher religiosity than people interested in pursuing a career in chemistry/physics $(p=0.01)$. There was not a significant difference in degree of religiosity between individuals interested in pursuing a career in biology as compared to medicine.

People planning to or currently pursuing a career in evolutionary science have a significantly greater understanding of evolution than people choosing other careers, whether that is within biology or medicine or the physical sciences. Within the first evolution-understanding construct, people pursuing a career in evolutionary biology have a significantly greater understanding than those pursuing medicine $(\mathrm{p}=0.04)$ and those planning to go into chemistry/physics $(\mathrm{p}=0.02)$. Within the second evolution-understanding construct, we found people seeking careers in medicine show significantly less understanding of evolutionary principles than those pursuing either general biology $(p=0.005)$ or evolutionary biology $(p<0.008)$.

\section{Discussion}

Our ultimate goal was to obtain preliminary data that provided insight and could inform how we recruit and retain URM students in evolutionary science. Based on 
Table 6 ANOVA and Bonferroni corrected t-tests for career choice comparisons

\begin{tabular}{|c|c|c|c|c|c|c|c|c|}
\hline & \multicolumn{3}{|c|}{ ANOVA } & \multicolumn{5}{|c|}{ Bonferroni corrected t-tests } \\
\hline & F-stat & df & $\mathbf{p}$ & & & & & \\
\hline \multirow{4}{*}{$\begin{array}{l}\text { How important do you think evolutionary science is to } \\
\text { our global society? }\end{array}$} & 3.611 & 178 & 0.007 & & Evo & Med & Ch/Phys & Other \\
\hline & & & & Bio & 0.09 & 0.32 & 1.00 & 1.00 \\
\hline & & & & Evo & -- & 0.004 & 0.06 & 1.00 \\
\hline & & & & Med & -- & -- & 1.00 & 0.40 \\
\hline \multirow{4}{*}{$\begin{array}{l}\text { What is your current level of interest in evolutionary science } \\
\text { as an academic discipline? }\end{array}$} & 7.427 & 179 & $<0.001$ & & Evo & Med & Ch/Phys & Other \\
\hline & & & & Bio & $<0.001$ & 0.13 & 1.00 & 1.00 \\
\hline & & & & Evo & -- & $<0.001$ & 0.001 & 0.20 \\
\hline & & & & Med & -- & -- & 1.00 & 0.40 \\
\hline \multirow{4}{*}{$\begin{array}{l}\text { Please rate you understanding of what an academic evolutionary } \\
\text { scientist does on a daily basis. }\end{array}$} & 3.499 & 179 & 0.009 & & Evo & Med & Ch/Phys & Other \\
\hline & & & & Bio & 0.08 & 0.51 & 1.00 & 1.00 \\
\hline & & & & Evo & -- & 0.005 & 0.33 & 1.00 \\
\hline & & & & Med & -- & -- & 0.91 & 0.22 \\
\hline \multirow[t]{4}{*}{ Religiosity } & 5.323 & 172 & $<0.001$ & & Evo & Med & Ch/Phys & Other \\
\hline & & & & Bio & 0.04 & 0.07 & & \\
\hline & & & & Evo & -- & $<0.001$ & 0.33 & 0.28 \\
\hline & & & & Med & -- & -- & 0.01 & 0.60 \\
\hline \multirow[t]{4}{*}{ Understanding (Factor 1) } & 6.234 & 176 & $<0.001$ & & Evo & Med & Ch/Phys & Other \\
\hline & & & & Bio & 0.77 & 0.21 & 0.17 & 0.006 \\
\hline & & & & Evo & -- & 0.04 & 0.03 & 0.002 \\
\hline & & & & Med & -- & -- & 1.00 & 1.00 \\
\hline \multirow[t]{4}{*}{ Understanding (Factor 2) } & 5.123 & 173 & $<0.001$ & & Evo & Med & Ch/Phys & Other \\
\hline & & & & Bio & 1.00 & 0.005 & 0.25 & 1.00 \\
\hline & & & & Evo & -- & 0.008 & 0.11 & 1.00 \\
\hline & & & & Med & -- & -- & 1.00 & 0.05 \\
\hline
\end{tabular}

our survey of 184 students exhibiting interests in pursuing careers in science, URM students do show differences, when compared to European American students, in factors that appear to influence their career paths, as well as the specific disciplines they choose to pursue. We also identified differences between URM groups in terms of their interest in, and understanding of, evolutionary biology, and identified differences among those students intending on pursuing career paths in evolutionary biology as compared to careers in other biological sciences. We have noted several patterns that may start to explain why underrepresented minorities are less likely to choose careers in evolutionary science, and some possible recommendations for future research.

Factors influencing the career choices of scientificallyinterested URM students

Our data suggest a few factors that may be important as URM students consider disciplines to pursue beyond their undergraduate training. We observed differences among URM groups with respect to exposure to science and the presence of individuals of similar racial/ethnic background currently working in the discipline appears important for African Americans and non-Puerto Rican Latino/a(s). Of potential importance is the difference between Puerto Ricans and non-Puerto Rican Latino(a)s with regard to the influence of similar individuals in the field. Puerto Rican youths who grow up in Puerto Rico, a society where their day-to-day role models are also Puerto Rican (police, teachers, ministers, politicians, etc.), may see individuals like themselves in fields that can be dominated by European Americans in other regions of the United States. Other studies have found URM success in STEM programs is tied to self-efficacy, and identifying as a scientist (Chemers et al. 2011; Merolla and Serpe 2013). These combined results reiterate the importance of providing URM students interested in STEM disciplines an opportunity to interact with other URM scientists as role models or mentors.

In addition, African Americans exhibited higher rates of religiosity, and perhaps most important for our attempts to recruit African Americans into evolutionary biology, 
significantly higher rates of religiosity when compared to other URM groups. These findings concur with those of Bailey et al. (2011), who found higher rates of religiosity among African American undergraduate non-majors. These data suggest additional challenges to recruiting African American students into the sciences, and in particular, to disciplines that require an understanding of evolution, which can clearly conflict with many religious beliefs.

\section{Factors influencing URM students to choose careers in evolutionary science}

Of the 126 URMs who were biology majors, only 8 identified themselves as interested in pursuing careers in evolutionary biology (1 African American, 7 Hispanic/ Latino(a)s); no Native Americans indicated an interest in evolutionary biology. Despite the fact that we biased our sample toward URM students interested in STEM fields, we still found European Americans 1.5 to 5 times more likely to be interested in a career in evolutionary biology when compared to Hispanic/Latino(a)s or African Americans, respectively. Significant differences in understanding of evolution may help explain these results. Among those URM students choosing careers in STEM fields, those pursing medicine and non-biological fields such as chemistry and physics exhibited more misconceptions, and those pursing medicine specifically showed lower overall understanding of evolutionary processes. With respect to recruiting and retaining URM students into evolutionary biology, these findings are potentially worrisome if we are to assume the population we sampled represents highly trained STEM students.

Religiosity may also contribute to career choices, particularly when it comes to evolutionary biology. Perhaps not surprisingly, URM students indicating an interest in evolutionary biology were significantly less religious than those pursuing careers in biological sciences in general, and medicine in particular. We also found proportionally more African Americans chose careers in medicine. Higher rates of religiosity may drive African Americans to choose disciplines that do not require training in evolutionary biology, perhaps to minimize conflict with their religious beliefs. Despite recent calls for the inclusion of evolution into medical school curriculum (Stearns 2011; Alcock and Schwartz 2011; Meikle and Scott 2011; National Research Council and National Academy of Sciences 2012 Thinking Evolutionarily), evolutionary medicine is still viewed as an elective.

Our results suggest that religiosity may be of greater importance to African Americans than other URM groups in deciding to pursue a career in evolutionary biology. Although a great deal of research exists that demonstrates socioeconomic, religious, and educational effects are correlated with evolution acceptance (Hawley et al., 2011), the ultimate cause and effect between religiosity and evolution understanding is still unclear. Do African Americans have a poorer understanding of evolution because they believe that evolutionary theory is in opposition to their religious beliefs, and thus ignore or dismiss the subject of evolution when it is taught in school? Or do African Americans receive less exposure to evolution in school than do European Americans or other URMs, limiting their opportunity to learn about the topic in the first place?

States differ in their expected support for evolution in the elementary and secondary school system. It is relevant that the distributions of African American and Hispanic populations differ by state from that of European Americans (U.S. Bureau of the Census, 2012). In 2009, the grading of state science standards relative to the teaching of evolution in public schools was reported (Mead and Mates 2009). Based on these grades, the mean grade for states with the highest numbers of African Americans was 2.30 (C-) but for Hispanic Americans was $2.70(\mathrm{C}+$ ), compared to European Americans at 3.00 (B-). Bailey et al. (2011) reported minimum exposure to evolution in high school courses (rank 1.97 on a 5-point Likert scale) among African American students in their study. It is not difficult to imagine how a self-reinforcing cycle of low understanding and enthusiasm for evolution may develop in African American communities. This cycle, in concert with resistance to evolution for religious reasons, may lead to lower preferences for evolutionary science careers among African Americans.

\section{Conclusion}

We sought to explore potential variables influencing career choices among URM students interested in science, with a particular focus on factors that influence URM students to choose a career in evolutionary biology. Of the 126 URMs surveyed who were biology majors, only 8 identified themselves as interested in pursuing an evolutionary science careers (1 African American, 7 Hispanic/ Latino(a)s). Our results emphasize the importance of exposing URM students to African American and Hispanic/ Latino(a) evolutionary biologists, in an effort to increase the opportunities that these students see themselves as evolutionary scientists. In addition, religiosity and evolution understanding were clearly correlated with a lack of diversity in the evolutionary sciences. African Americans, in particular, showed higher religiosity and lower understanding of evolution compared with Hispanic/Latino(a) participants, pointing to the need to address these factors within African American communities specifically.

Our findings also highlight the importance of including analysis of racial/ethnic data when investigating factors influencing evolution acceptance and understanding. Continued analysis of these factors will increase our 
understanding of why URMs are not pursuing evolutionary science, allowing us to take steps to address these factors. Educators, researchers, and equality advocates can then target specific causes for underrepresentation in the evolutionary sciences and work towards more equal representation.

An important next step to improving the understanding of why URMs are not pursuing evolutionary science as a career is to survey larger and more diverse populations across the United States. Future large-scale studies at a wide range of universities and colleges across America, targeting URM career choice in STEM and non-STEM fields, would provide a wealth of information about the reasoning for career choice, as well as how career choice and ethnicity relate to evolution understanding and acceptance.

\section{Additional files}

Below is the link to the electronic supplementary material.

\section{Additional file 1: Table S1. A review of published studies that}

investigate the acceptance of evolution among college undergraduates (Fuerst 1984; Johnson and Peebles 1987; Blackwell et al. 2003; Brem et al. 2003; Sinatra et al. 2003; Ingram and Nelson 2006; Rutledge and Sadler 2007; Hokayem and BouJaoude 2008; Lombrozo et al. 2008; Cunning and Wescott 2009; Moore et al. 2009; Paz-y-Mino and Espinosa 2009a; Paz-yMino and Espinosa 2009b; Rice et al. 2011; Bailey et al. 2011; Hawley et al. 2011; Paz-y-Miño and Espinosa 2011; Ha et al. 2012; Rissler et al. 2014).

Additional file 2: Table S2. SACNAS / ABRCMS Survey.

\section{Competing interest}

The authors declared that they have no competing interests.

\section{Authors' contributions}

The initial idea for the study arose out of a catalysis meeting at the National Evolutionary Synthesis Center, organized by JBC, JLG, and LSM. This catalysis meeting was attended by evolutionary science researchers as well as researchers in evolution education. In addition, many of the participants were from the minority groups that were the subject of this study. LSM and $\mathrm{JBC}$ managed the project. All authors contributed to the creation of the survey. FF administered the survey at the two conferences mentioned in the paper and conducted the statistical analyses. All authors contributed to writing portions of the manuscript, and LSM revised manuscript according to reviewer comments. All authors read and approved the final manuscript.

\section{Acknowledgements}

We would like to thank Emily Stafford for reading and reviewing early versions of the manuscript and two anonymous reviewers for comments on the initial submission. The BEACON Center for the Study of Evolution in Action funded the project.

\footnotetext{
Author details

'BEACON Center for the Study of Evolution in Action, Michigan State University, 567 Wilson Ave BPS 1441, East Lansing, MI, 49925, USA. ${ }^{2}$ Geosciences \& Natural Resources Department, Western Carolina University, College of Arts and Sciences, 331 Stillwell Building Western Carolina University, Cullowhee, NC, 28723, USA. ${ }^{3}$ Joint School of Nanoscience \& Nanoengineering, North Carolina A\&T State University and UNC Greensboro, 2907 E. Lee St, Greensboro, NC, 27401, USA.
}

Received: 7 July 2014 Accepted: 8 January 2015

Published online: 22 February 2015

\section{References}

Alcock J, Schwartz MD. A clinical perspective in evolutionary medicine: What we wish we had learned in medical school. Evolution: Education and Outreach. 2011;4:574-9.

Back T. Evolutionary Algorithms in Theory and Practice: Evolution Strategies, Evolutionary Programming, Genetic Algorithms. Oxford, UK: Oxford University Press; 1996

Bailey G, Han J, Wright D, Graves JL. Religiously expressed fatalism and the perceived need for science and scientific process to empower agency. The International Journal Science in Society. 2011;2(3):55-88.

Blackwell WH, Powell JM, Dukes GH. The problem of student acceptance of evolution. Journal of Biological Education. 2003;37:58-67.

Brem SK, Ranney M, Schindel J. Perceived consequences of evolution: College students perceive negative personal and social impact in evolutionary theory. Science Education. 2003;87:181-206.

Chemers MM, Zugriggen EL, Syed M, Goza B, Bearman S. The role of efficacy and identity in science career commitment among underrepresented minority students. Journal of Social Issues. 2011;67:469-91.

Coello CC, Lamont GB, Van Veldhuizen DA, et al. Evolutionary algorithms for solving multi-objective problems. New York, NY: Springer; 2007.

Cunningham DL, Wescott DJ. Still more "fancy" and "myth" than "fact" in students' conceptions of evolution. Evolution: Education and Outreach. 2009;2:505-17.

Dufour DL. Biocultural approaches to human biology. American Journal of Human Biology. 2006;18:1-9.

Eccles J. Understanding educational and occupational choices. Journal of Social Issues. 2011;67:644-8.

Fuerst PA. University student understanding of evolutionary biology's place in the Creation/Evolution theory. The Ohio Journal of Science. 1984;84:218-28.

Gallop (2014) "Values and Beliefs". Questions 21 and 22, May 8-11, 2014, in Gallup Poll Social Series. Retrieved from http://www.gallup.com/poll/170822/ believecreationist-view-human-origins.aspx

Graves JL. Evolutionary versus Racial Medicine: Why it Matters? In: Krimsky S, editor. Race and the Genetic Revolution: Science, Myth and Culture. New York, NY: Columbia University Press; 2011.

Graves JL. Science in the Belly of the Beast: A Look Back at My Career in the Academy. In: Farmer VL, Shepherd-Wynn E, editors. Voices of Historical and Contemporary Black American Pioneers. Westport, CT: Praeger Publishers; 2012.

Gregory TR. Evolution as fact, theory, and path. Evolution: Education and Outreach. 2008;1:46-52.

Ha M, Haury DL, Nehm RH. Feeling of certainty: Uncovering a missing link between knowledge and acceptance of evolution. Journal of Research in Science Teaching. 2012:49:95-121.

Hawley PH, Short SD, McCune LA, Osman MR, Little TD. What's the matter with Kansas?: The development and confirmation of the evolutionary attitudes and literacy survey (EALS). Evolution: Education and Outreach. 2011;4:117-32.

Hokayem H, BouJaoude S. College students' perceptions of the theory of evolution. Journal of Research on Science Teaching. 2008:45:395-419.

Ingram EL, Nelson CE. Relationship between achievement and students' acceptance of evolution or creation in an upper-level evolution course. Journal of Research in Science Teaching. 2006;43:7-24.

Jaeger AJ, Haley KJ, Ampaw FD, Levin JS. Understanding the career choice for underrepresented minority doctoral students in science and engineering. Journal Women and Minorities in Science Ed. 2013;19:1-16.

Johnson RL, Peebles EE. Understanding in college student acceptance of evolution. The American Biology Teacher. 1987;49:93-8.

Khachatourians GG. Agricultural use of antibiotics and the evolution and transfer of antibiotic-resistant bacteria. Canadian Medical Association Journal. 1998;159:1129-36.

Larder BA, Darby G, Richman DD. HIV with reduced sensitivity to Zidovudine (AZT) isolated during prolonged therapy. Science. 1989;243:1731-4.

Lombrozo T, Thanukos A, Weisberg M. The Importance of Understanding the Nature of Science for Accepting Evolution. Evolution: Education and Outreach. 2008; 1:290-8.

MacPhee D, Farro S, Canetto SS. Academic self-efficacy and performance of underrepresented STEM majors: gender, ethnic, and social class patterns. Analyses of Social Issues and Public Policy. 2013;13:347-69.

Mead LS, Mates A. Why science standards are important to a strong science curriculum and how states measure up. Evolution: Education and Outreach. 2009;2:359-71. 
Meikle E, Scott E. Evolutionary medicine: A key to introducing evolution. Evolution: Education and Outreach. 2011:4:644-7.

Merolla DM, Serpe RT. STEM enrichment programs and graduate school matriculation: the role of science identity salience. Social Psychology of Education. 2013;16:575-97

Miller J, Scott EC, Okamoto S. Public acceptance of evolution. Science. 2006;313:765-6.

Moore R, Cotner S, Bates A. The influence of religion and high school biology courses on students' knowledge of evolution when the enter college. The Journal of Effective Teaching. 2009;9:4-12.

National Research Council and National Academy of Sciences. Thinking Evolutionarily: Evolution Education Across the Life Sciences. Summary of a Convocation. In: Steve Olson, Rapporteur. Planning Committee on Thinking Evolutionarily: Making Biology Education Make Sense. Board on Life Sciences, Division on Earth and Life Studies, National Research Council, and National Academy of Sciences. Washington, DC: The National Academies Press; 2012.

National Science Foundation, National Center for Science and Engineering Statistics. 2012. Doctorate Recipients from U.S. Universities: 2011. Special Report NSF 13-301. Arlington, VA. Available at http://www.nsf.gov/statistics/sed/

Nesse RM, Williams GC (1996). Why We Get Sick: The New Science of Darwinian Medicine. New York: Vintage.

Paz-y-Miño CG, Espinosa A. New England faculty and college students differ in their views about evolution, creationism, intelligent design, and religiosity. Evolution: Education and Outreach. 2011:4:323-42.

Paz-y-Minos G, Espinosa A. Assessment of biology majors' versus nonmajors' views on evolution, creationism, and intelligent design. Evolution: Education and Outreach. 2009a;2:75-83.

Paz-y-Minos G, Espinosa A. Acceptance of evolution increases with student academic level: A comparison between a secular and religious college. Evolution: Education and Outreach. 2009b;2:655-75.

Perron GC, Zasloff M, Bell G. Experimental evolution of the resistance of an antimicrobial peptide. Proc Royal Society B: Biological Sciences. 2006;273:251-6.

Pew Research Center (2009) "General Public Science Survey" April 28-May12, 2009. Retrieved from http://www.pewforum.org/2009/11/05/public-opinionon-religion-and-science-in-the-united-states/.

Pew Research Center (2013) "Publics Views on Human Evolution" March 21-April 8, 2013. Retrieved from http://www.pewforum.org/2013/12/30/publics-viewson-humanevolution/.

Pike IL, Williams SR. Incorporating psychosocial health into biocultural models: preliminary findings from Turkana women of Kenya. American Journal of Human Biology. 2006;18(6):729-40.

R Development Core Team. R: A language and environment for statistical computing. Vienna, Austria: R Foundation for Statistical Computing; 2013 http://www.R-project.org.

Rice J, Olson JK, Colbert JT. University Evolution Education: The Effect of Evolution Instruction on Biology Majors' Content Knowledge, Attitude Toward Evolution, and Theistic Position. Evolution: Education and Outreach. 2011;4:137-44.

Rissler LJ, Duncan SI, Caruso NM. The relative importance of religion and education on university students' views of evolution in the Deep South and state science standards across the United States. Evolution: Education and Outreach. 2014;7:22

Rutledge ML, Sadler KC. Reliability of the Measure of Acceptance of the Theory of Evolution instrument with university students. American Biology Teacher. 2007;69:332-5.

Sinatra GM, Southerland SA, McConaughy F, Demastes JW. Intentions and beliefs in students' understanding and acceptance of biological evolution. Journal of Research in Science Teaching. 2003:40:510-48.

Stearns SS. On designing courses in evolutionary medicine. Evolution: Education and Outreach. 2011:4:589-94.

Thoman, DB, Brown, ER, Mason, AZ, Harmsen, AG, Smith, JL (2014). The role of altruistic values in motivating underrepresented minority students for biomedicine. BioScience, first published online December 10, 2014

U.S. Census Bureau, Statistical Abstract of the United State: 2012 (131st Edition) Washington, DC, 2011; https://www.census.gov/compendia/statab/

\section{Submit your manuscript to a SpringerOpen ${ }^{\circ}$ journal and benefit from:}

- Convenient online submission

- Rigorous peer review

- Immediate publication on acceptance

- Open access: articles freely available online

- High visibility within the field

Retaining the copyright to your article

Submit your next manuscript at $>$ springeropen.com 